\title{
Decellularization protocols of porcine heart valves differ importantly in efficiency of cell removal and susceptibility of the matrix to recellularization with human vascular cells
}

\author{
Erwin Rieder, MD \\ Marie-Theres Kasimir, MD \\ Gerd Silberhumer, MD \\ Gernot Seebacher, MD \\ Ernst Wolner, MD \\ Paul Simon, MD \\ Guenter Weigel, MD
}

\footnotetext{
From the Department of Cardiothoracic Surgery and Ludwig-Boltzmann-Institute for Cardiosurgical Research, University of Vienna, Vienna, Austria.

Received for publication March 22, 2003; revisions received May 1, 2003; accepted for publication June 23, 2003

Address for reprints: Guenter Weigel, MD, Department of Cardiothoracic Surgery, University of Vienna, AKH, Waehringer Guertel 18-20, 1090 Vienna, Austria (Email: guenter.weigel@akh-wien.ac.at).

J Thorac Cardiovasc Surg 2004;127: $399-405$

$0022-5223 / \$ 30.00$
}

Copyright () 2004 by The American Association for Thoracic Surgery

doi:10.1016/j.jtcvs.2003.06.017
Objective: We compared 3 different decellularization protocols in porcine heart valves for efficiency of complete cell removal and potential for recellularization.

Methods: Porcine aortic and pulmonary roots were treated with trypsin, sodiumdodecyl-sulphate, or a new method using $0.25 \%$ tert-octylphenyl-polyoxyethylen in combination with sodium-deoxycholate. After a subsequent ribonuclease digestion, specimens were seeded with in vitro expanded human saphenous vein endothelial cells and myofibroblasts.

Results: After treatment with trypsin and subsequent ribonuclease digestion, endothelial attachment took place; however, xenogenic cells were still visible within the matrix. Unexpectedly, when human cells were seeded onto specimens that had been decellularized with sodium-dodecyl-sulphate, the matrices were surrounded by nonviable endothelial cell fragments, indicating a toxic influence of the ionic detergent; $0.25 \%$ tert-octylphenyl-polyoxyethylen together with sodium-deoxycholate completely removed porcine cells and enabled host recellularization.

Conclusion: Compared with trypsin and sodium-dodecyl-sulphate involving decellularization procedures, reported to be effective in cell removal and susceptible to recellularization with human cells, only the porcine matrix treated with a new detergent-based decellularization method using $0.25 \%$ tert-octylphenyl-polyoxyethylen/sodium-deoxycholate followed by nuclease digestion presented an excellent scaffold for recellularization with human cells.

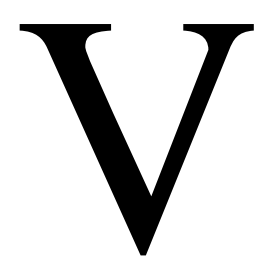

alvular heart disease is an important cause of morbidity and mortality. Currently available prostheses are associated with major limitations. Mechanical valve substitutes require lifelong anticoagulation, can cause serious thromboembolic and bleeding complications, and are susceptible to infection. ${ }^{1}$ Although bioprosthetic heart valves have proved clinically successful over the short term, their long-term performance needs improvement. ${ }^{2,3}$

Human allografts eliminate the need of anticoagulation and have the best hemodynamic properties, but their availability is limited. None of these currently used heart valve substitutes shows any growth potential or regeneration capability, which would play an important role especially in the treatment of pediatric patients.

Tissue engineering of heart valves is a multidisciplinary approach to overcome these limitations. The created autologous living replacement structure should have the ability to self-repair, remodel, and thereby increase durability without the risk of rejection and ideally even grow. 
The initial and crucial step is to obtain an optimal valve matrix. ${ }^{4,5}$ We have chosen the concept of using a decellularized xenogenous heart valve.

The aim of this study was to test different decellularization protocols for their efficiency of complete cell removal and ability to produce a matrix with excellent recellularization susceptibility with human cells.

\section{Material and Methods}

\section{Decellularization of Porcine Heart Valve Tissue}

Porcine pulmonary (PV; $\mathrm{n}=16$ ) and aortic heart valve conduits $(\mathrm{AV} ; \mathrm{n}=14)$ were obtained from a local slaughterhouse and excised of adherent fat and myocardium. For comparison with native untreated valves a root specimen and 1 leaflet of each conduit were excised and further processed for scanning electron microscopy (SEM) and laser scanning microscopy (LSM). The heart valves were incubated for 24 hours with a solution containing multiple antibiotics for sterilization.

Three different decellularization protocols were used for comparison, of which 2 have been described ${ }^{5-8}$ and the third was developed in our laboratory, using 2 detergents formerly used for cell extraction ${ }^{9}$ in combination with ribonuclease digestion and to our knowledge has not been published before.

In the first group the valve conduits $(\mathrm{PV}=5, \mathrm{AV}=4)$ were treated with $0.1 \%$ trypsin (Gibco, Paisley, Scotland, UK) with $0.02 \%$ ethylenediaminetetraacetic acid (EDTA; Merck, Darmstadt, Germany) in phosphate-buffered saline solution without $\mathrm{Ca}^{2+}$ and $\mathrm{Mg}^{2+}$ (PBS ${ }^{-1-}$, Gibco) for 48 hours. In the second group valve conduits $(\mathrm{PV}=4, \mathrm{AV}=3$ ) were treated with $0.1 \%$ sodiumdodecyl-sulphate (SDS; BioRad, Hercules, Calif) in $\mathrm{PBS}^{-1-}$ for 24 hours. Treatment in group 3 ( $\mathrm{PV}=7, \mathrm{AV}=7$ ) is a detergentbased decellularization mixture consisting of a 24-hour incubation period with $0.25 \%$ tert-octylphenyl-polyoxyethylen (Triton X-100, BioRad) plus $0.25 \%$ sodium-deoxycholate (Merck) in $\mathrm{PBS}^{-\prime-}$ at $37^{\circ} \mathrm{C}$, followed by a intensive wash cycle with M-199 medium (Gibco) for 72 hours at $4^{\circ} \mathrm{C}$ to remove residual substances. All specimens were subsequently treated by a nuclease digestion with ribonuclease $(100 \mu \mathrm{g} / \mathrm{mL}$; RNase, Roche Diagnostics Gmbh, Mannheim, Germany) and deoxyribonuclease (150 IU/mL; DNase, Sigma, St Louis, Mo) with $50 \mathrm{mmol} / \mathrm{L} \mathrm{MgCl}_{2}$ in $\mathrm{PBS}^{-\prime-}$ for 24 hours at $37^{\circ} \mathrm{C}$ to remove remaining nucleic remnants. Samples were again washed with M-199 medium for 24 hours at $4^{\circ} \mathrm{C}$. All steps were conducted under continuous shaking.

\section{Cell Separation and Expansion}

Human saphenous vein endothelial cells (HSVEC) were harvested from discarded segments of vena saphena magna of patients undergoing coronary artery bypass surgery. In brief, the veins were cannulated and flushed with sterile $\mathrm{PBS}^{-1-}$ under sterile conditions. The lumen was then filled with $0.2 \%$ collagenase type II (Gibco) solution and left at room temperature for 15 minutes. To dislodge the loosened endothelial cells the vein was gently massaged and flushed with M-199 medium. The HSVEC were pelleted by centrifugation for 5 minutes at $300 g$ and thereafter resuspended in culture medium consisting of M-199 medium, 20\% pooled human serum, $100 \mu \mathrm{g} / \mathrm{mL}$ heparin (Sigma), $100 \mathrm{U} / \mathrm{mL}$ penicillin, and $100 \mu \mathrm{g} / \mathrm{mL}$ streptomycin (Gibco) and $30 \mathrm{mg} / \mathrm{L}$ endothelial cell growth supplement (Upstate, Lake Placid, NY). ${ }^{10}$ The cell suspension was transferred to a $25-\mathrm{cm}^{2}$ culture flask. Endothelial cells were maintained in a humidified incubator at $37^{\circ} \mathrm{C}$ and $5 \% \mathrm{CO}_{2}$ and the culture medium was changed every fourth or fifth day. Confluent HSVEC were detached using $0.05 \%$ trypsin/EDTA in $\mathrm{PBS}^{-1-}$ and subcultured. Purity of cells was evaluated by factor VIII (FVIII: vWF) staining, ${ }^{11}$ transmission electron microscopy (presence of Weibel-Pallade bodies), and expression of CD62E (E-selectin). No contamination by myocytes or fibroblasts was detected.

The remaining vessel was minced and pieces of 1 to $2 \mathrm{~mm}^{2}$ were placed into a $25-\mathrm{cm}^{2}$ culture flask with myofibroblast culture medium containing Dulbeco's modified Eagle's medium (BioWhittaker Europe, Verviers, Belgium), $100 \mathrm{U} / \mathrm{mL}$ penicillin, and $100 \mu \mathrm{g} / \mathrm{mL}$ streptomycin until saphenous vein media cells grew out onto the surface of the culture flask. Confluent cell cultures were subcultured with $0.05 \%$ trypsin/EDTA in $\mathrm{PBS}^{-\prime-}$.

\section{Cell Seeding}

The seeding susceptibility of the 3 differently decellularized porcine heart valve matrices was compared without any pretreatment of the matrices. Each valve conduit was divided and leaflets were dissected. Two $100-\mathrm{mm}^{2}$ specimens of the pulmonary or aortic root, as well as 2 leaflets of each conduit, were placed into a culture dish and seeded under static conditions with either $1 \times$ $10^{4} / \mathrm{mm}^{2}$ HSVEC or $2 \times 10^{4} / \mathrm{mm}^{2}$ saphenous vein myofibroblasts (only HSVEC were seeded onto SDS-treated specimens). Afterward, the specimens were incubated in a humidified environment at $37^{\circ} \mathrm{C}$ and $5 \% \mathrm{CO}_{2}$ either for 5 days (HSVEC) or 10 days (myofibroblasts).

\section{Biocompatibility of SDS Treatment}

To examine a possible toxic influence of SDS released from decellularized specimens, increasing concentrations (10\%-30\% $\mathrm{v} / \mathrm{v}$ ) of $\mathrm{PBS}^{-1-}$, used to store the SDS-treated root specimens, were added to culture medium of in vitro cultured endothelial cells (EC) and compared with the influence of $\mathrm{PBS}^{-1-}$ that was not used for storing specimens.

\section{Morphological Analysis}

The specimens were either fixed by immersion in $2.5 \%$ glutaraldehyde for at least 24 hours and further processed for SEM or embedded in Tissue Tek OCT Compound (Sakura, Zoeterwoude, The Netherlands). Five cryostat sections (10 $\mu \mathrm{m})$ of each specimen were stained for the production of von Willebrand factor (antivWf, Serotec, Düsseldorf, Germany) to analyze the viability of the transplanted HSVEC. The DNA-specific dye TO-PRO 3 (Molecular Probes, Leiden, The Netherlands) was used to assess the removal of xenogenous cells or nuclei in the porcine matrix.

The sections were also stained with an anti-porcine collagen type I and III antibody (Monosan, Uden, The Netherlands), shown to be cross-reactive with human type I/III collagen, and with an anti-elastin antibody (monoclonal anti-elastin, Clone BA-4, Sigma) to examine structural alterations of the matrix fibers.

Cryostat section was scanned for remaining cell remnants with a Zeiss LSM 510 laser scanning microscope (Zeiss, Jena, Germany) using the 3-dimensional analysis mode and representative micrographs are shown. 


\section{Results}

Electron microscopic examination of the group 1 matrix specimens $(n=36)$ treated with trypsin/EDTA demonstrated the typical cobblestone morphology of a completely confluent endothelial cell monolayer $(\mathrm{n}=18$, Figure $1, A$, $B)$. The venous media cells attached to the surface of the xenogenous tissue in a patchy distribution $(\mathrm{n}=18$, not shown). Confocal microscopic examination revealed viable EC staining positive for vWf, as these appeared as thin, bright, confluent red layer on the surface of the pulmonary and aortic wall as well as on the leaflets. It appeared that the media cells started to synthesize collagen. However, porcine cells were still detectable in the matrix after decellularization (Figure 2, $A, B$ ).

When human cells were seeded onto SDS-treated pulmonary or aortic root specimens (Figure 2, C) in group 2 (n $=14$ ), no cell attachment took place but a massive cell lysis was observed within 24 hours of incubation. On examining the leaflets $(n=14)$, a patchy distribution $(n=8)$ or cell lysis $(n=6)$ of HSVEC could be seen but no confluence was reached even after 5 days of incubation.

Increasing concentrations (10\%-30\%) of $\mathrm{PBS}^{-1-}$, used to store the SDS-treated root-specimen, added to culture medium of in vitro cultured HSVEC revealed a decreasing amount of attached and viable endothelial cells in the culture flasks within 24 hours. In contrast, the same amount of $\mathrm{PBS}^{-1-}$ that was not used for storage of SDS-treated specimens did not affect in vitro cell growth (Figure 3, $A$ to $D)$. This test for the biocompatibility of SDS treatment indicates that not even a prolonged washout of SDS removes residual ionic-detergent substances within root matrices.

The seeding of porcine heart valve tissue in the third group $(\mathrm{n}=56)$ treated with Triton X-100 plus sodiumdeoxycholate followed by incubation with RNAse/DNAse and an extensive washing procedure with M-199 medium resulted in a confluent HSVEC layer $(\mathrm{n}=28)$ as was already described for group 1 (Figure 1, C).

The TO-PRO 37 staining in the sections examined demonstrated no visible cells within the porcine pulmonary $(\mathrm{n}=$ $28)$ as well as aortic valve matrix $(\mathrm{n}=28)$ (Figure $2, D)$. Confocal microscopic examination of specimens seeded with media cells demonstrated the thin, bright green collagen-specific area surrounding the patchy attached human myofibroblasts illustrating viable and actively collagen producing cells. A representative micrograph is shown in Figure 4.

\section{Discussion}

One approach to obtain scaffold material for tissue engineering of heart valves is to use allogenic or xenogenic material that is decellularized. These matrices should
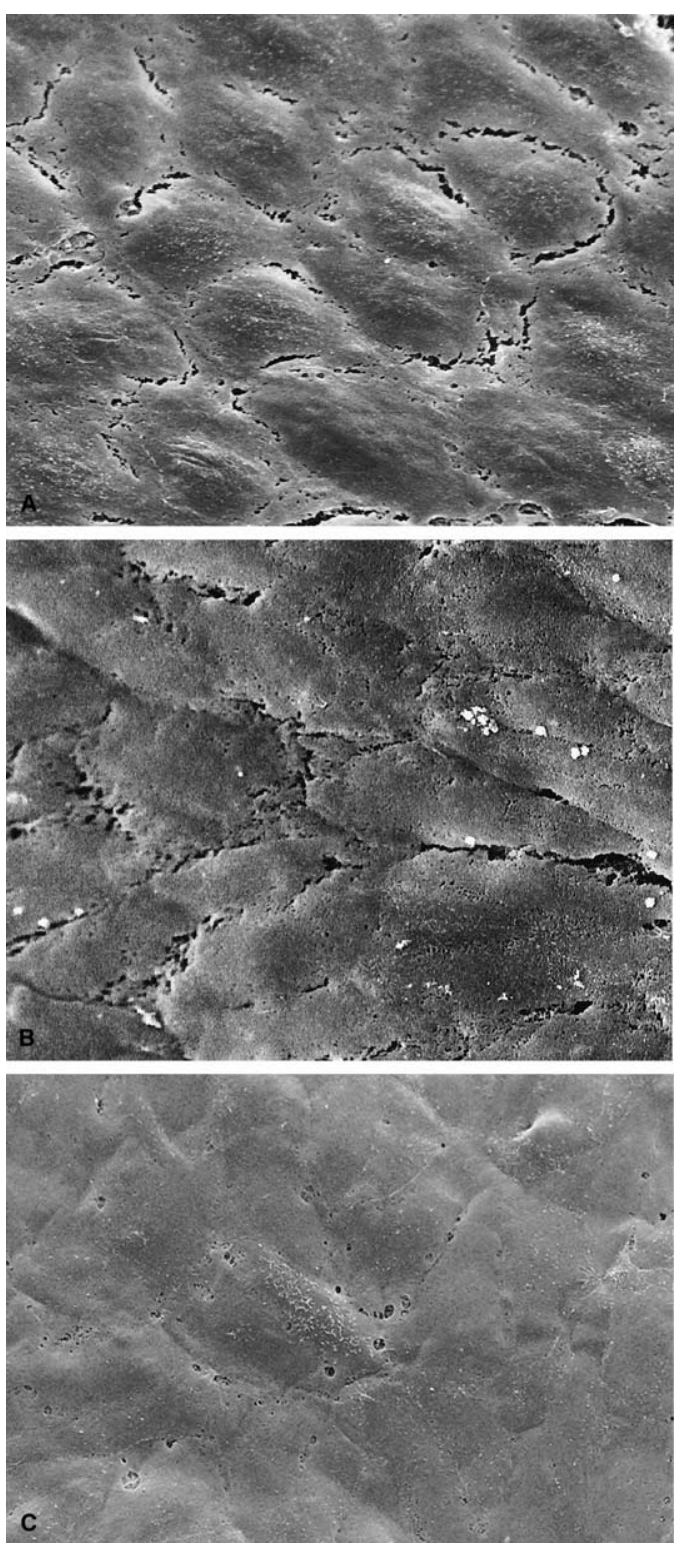

Figure 1. A, Native porcine aortic root (monolayer of endothelial cells); SEM $\times 750$. B, Porcine aortic wall after treatment with trypsin for 48 hours and seeded with in vitro expanded EC; SEM $\times 750$. C, Porcine aortic wall treated with Triton X-100/sodiumdeoxycholate and ribonuclease digestion. Seeded with expanded EC; SEM $\times 750$.

present an appropriate scaffold on which recipient autologous cells could be seeded.

Currently used glutaraldehyde cross-linked valves are mostly of porcine origin, ${ }^{2}$ though different reports according xenogeneic rejection patterns ${ }^{12-14}$ will need further investigation. Viral-associated risks ${ }^{15-17}$ should be considered when xenogenous tissue is used for tissue engineering. This was a reason to involve ribonuclease digestion within a decellularization procedure. Due to the limited availability 

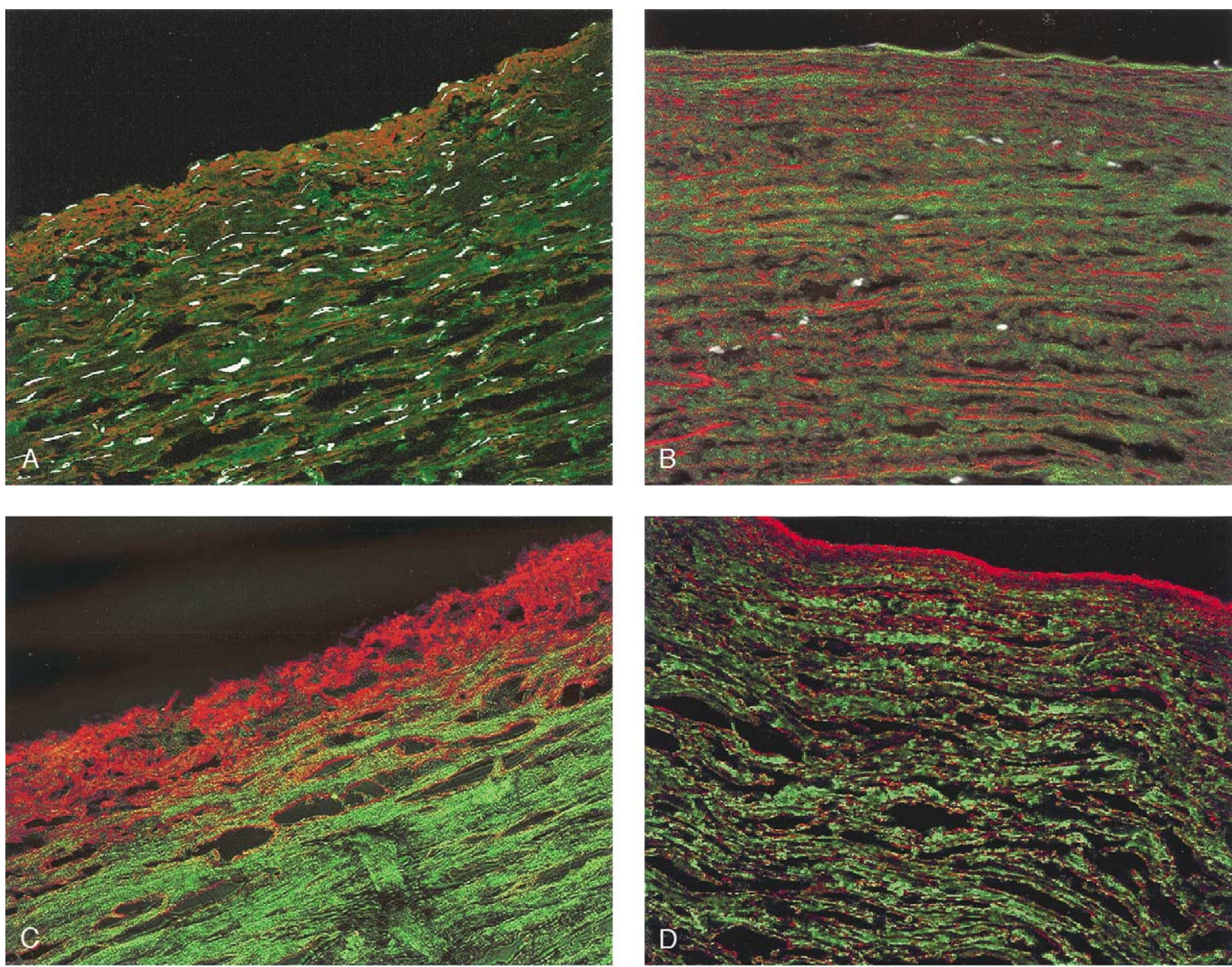

Figure 2. A, Native porcine aortic wall, staining for collagen I and III (green), elastin (red), and DNA (white); LSM $\times 400$. B, Group 1, porcine aortic wall after treatment with $0.1 \%$ trypsin, staining for collagen I and III (green), elastin (red), and DNA (white); LSM $\times 400$. C, Porcine aortic wall after treatment with $0.1 \%$ SDS, staining for collagen I and III (green), elastin (red), and DNA (white); LSM $\times 400$. D, Porcine aortic wall after treatment with $0.25 \%$ Triton X-100/0.25\% sodium-deoxycholate and nuclease digestion seeded with human EC, staining for vWF (red), collagen I and III (green), elastin (red), and DNA (white); LSM $\times 400$.

of human autologous heart valves the use of xenogenic valves is still of obvious advantage. Because vascular grafts placed in humans do not spontaneously form an endothelial monolayer, whereas they do in animals,${ }^{18}$ the importance of a confluent and viable endothelial cell layer on valve substitutes prior to implantation seems essential compared with other approaches. ${ }^{14,19}$ Seeding of vascular grafts with human autologous endothelial cells improves their long-term patency ${ }^{20,21}$ and reduces the thrombogenicity of cardiovascular implants. ${ }^{22}$

The recipient saphenous vein is an easily accessible cell source for seeding decellularized valves prior to implantation. Early experiments comparing allogenic and autologous cells favored the latter. ${ }^{23}$ The use of artery segments ${ }^{24}$ is unlikely to be transferable to the clinical situation.
Several decellularization methods involving detergents and/or enzymatic digestion have been described previously with some success but only very few reports have dealt with their susceptibility to seeding leaflet as well as root matrices.

In this study we demonstrate that the decellularization method of xenogenous heart valves is a crucial feature to obtain the optimal matrix for a tissue-engineered valve substitute. We found considerable differences in regard to the efficiency of complete xenogenous cell removal and the susceptibility to human cell attachment.

We as others found using trypsin ${ }^{5}$ or a nonionic detergent like Triton X-100 followed by ribonuclease digestion ${ }^{25}$ revealed only an incomplete removal of cells. Bader and colleagues $^{5}$ described that a longer incubation with trypsin 

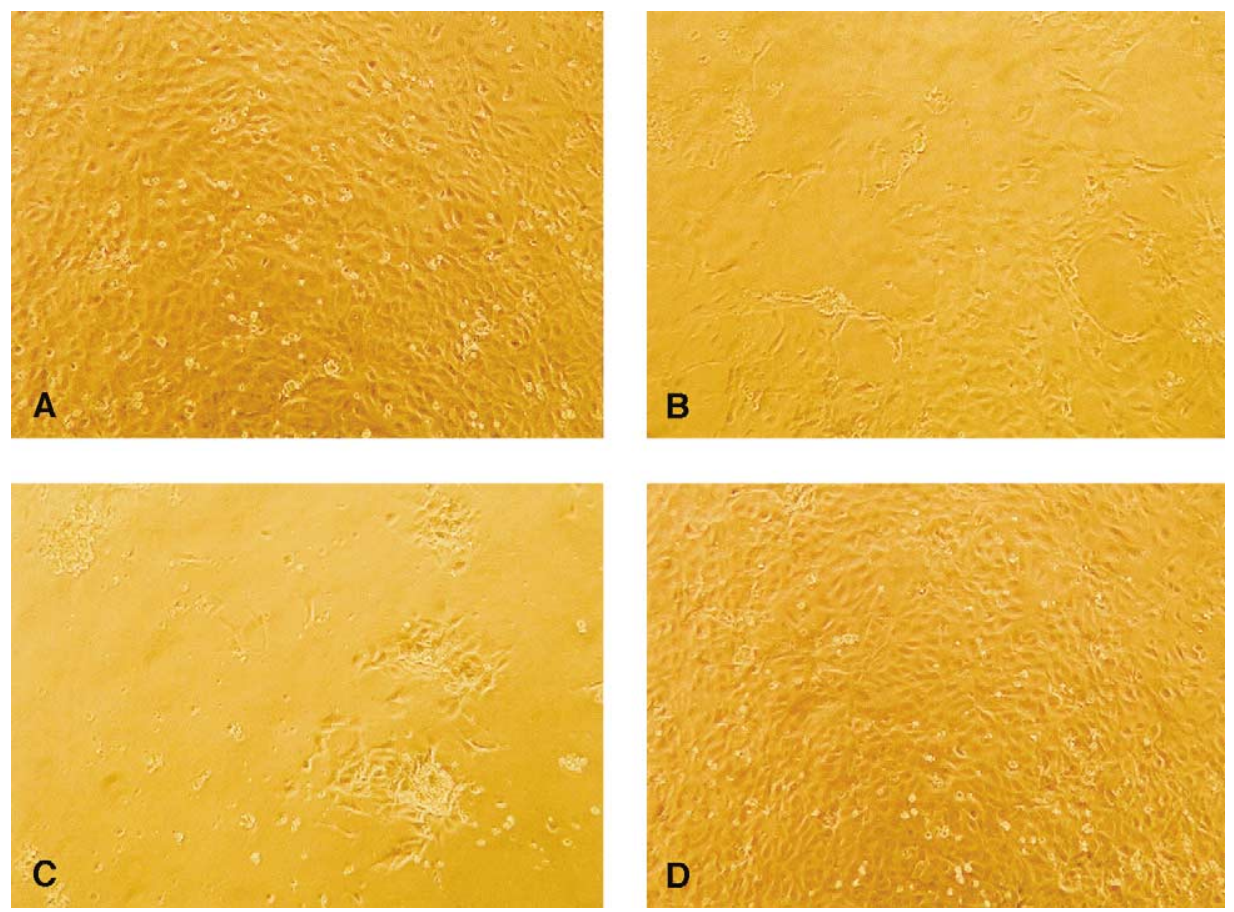

Figure 3. Increasing concentrations $(10 \%-30 \% \mathrm{v} / \mathrm{v})$ of $\mathrm{PBS}^{-1-}$ that was used to store SDS-treated specimens added to culture medium of in vitro cultured EC; light microscopy $\times \mathbf{4 0}$. (A) $10 \%$, (B) $20 \%$, (C) $30 \%$, (D) negative control (30\% of $\mathrm{PBS}^{-I-}$ that was not used to store SDS-treated specimens added to culture medium).

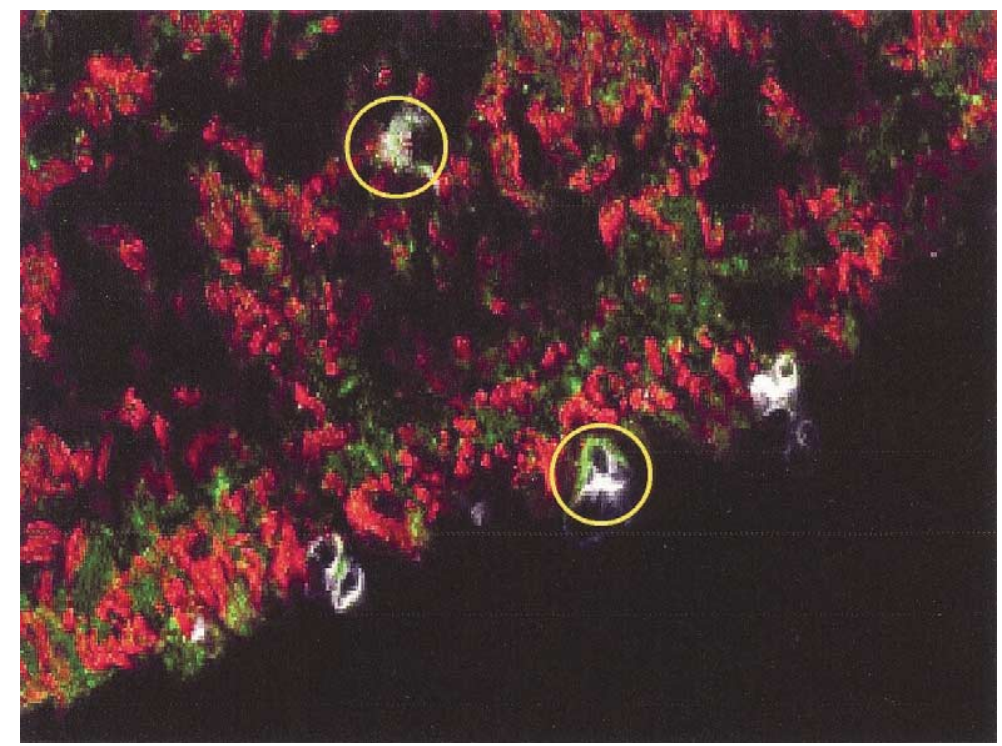

Figure 4. Collagen synthesis of myofibroblasts seeded onto porcine heart valve matrix treated with $0.25 \%$ Triton X-100/0.25\% sodium-deoxycholate and nuclease digestion, staining for collagen I and III (green), elastin (red), and DNA (white); LSM $\times 400$.

might be more effective in cell removal but causes a disruption of the matrix bundles. However, residual cells and cell remnants within the matrix might lead to calcification. ${ }^{12}$ As the naturally occurring alpha-gal antibodies in humans are interacting with alpha-gal epitopes ${ }^{26}$ on porcine cells, the efficient extraction of xenogenous cells is crucial. Otherwise an acute immunogenic response and early graft failure will follow. ${ }^{19}$ 
SDS treatment has previously been used to obtain complete acellularity ${ }^{7}$ but was also reported to destabilize the collagen triple helical domain and to swell the elastin network. ${ }^{9,27}$ However, these studies did not describe the seeding susceptibility. SDS is still described to be efficient for leaflet decellularization ${ }^{8}$ and was recently presented to be compatible for seeding of leaflets with endothelial cells. ${ }^{28}$ Although in our study SDS produced a biological matrix free of any visible xenogenous cells, it was impossible to seed the porcine aortic or pulmonary root specimens with human endothelial cells or myofibroblasts, as massive cell lysis occurred within 24 hours of incubation. This controversial finding might be due to probably higher levels of residual SDS remaining in the vascular wall. When increasing amounts of $\mathrm{PBS}^{---}$, which was used to store the SDS decellularized valve matrix after several days of washing, were added to culture medium of HSVEC, cell lysis occurred.

The findings of Kim and colleagues ${ }^{28}$ with respect to the seeding of leaflets might be explainable by the fact that the washing procedure is more effective when treating the much thinner valve leaflets. Because in a clinical setting the complete valve conduit will likely be used, the observation made by us seems crucial with respect to further studies involving SDS.

Our decellularization procedure, involving the combination of Triton X-100 and sodium-deoxycholate followed by a washing process with M-199 medium to remove any residual detergents and an enzymatic digestion with DNAse/RNAse to remove remaining nucleic acids, results in an excellent scaffold, free of any histologically detectable xenogenous cells or cell remnants, which is well suited for seeding with human cells. Transplanted endothelial cells and myofibroblasts remained viable. We could even demonstrate active collagen synthesis by human myofibroblasts attached to the xenogenous matrix. Although Triton and cholate treatment was presented not to affect the structural integrity of either elastin and collagen, ${ }^{9}$ further studies concerning mechanical testing are currently under investigation in our laboratory. Cell seeding under flow conditions should not have impact on the biocompatibility of xenogenous matrices, but cultivation under shear stress will provide the ability of proper adherence of seeded cells to acellular matrix surface and is also subject of current experiments.

We conclude from our findings that decellularization procedures used differ considerably in their efficiency of cell removal and susceptibility of the matrix to recellularization. Our newly developed method produces an excellently preserved xenogenic scaffold that fulfills both requirements, acellularity and high susceptibility to recellularization with human vascular cells.
We thank Anneliese Nigisch, Birgitta Winter, Eva Eichmair, Barbara Dekan, and Sabine Lehner for their excellent technical assistance.

\section{References}

1. Cannegieter SC, Rosendaal FR, Briet E. Thromboembolic and bleeding complications in patients with mechanical heart valve prostheses. Circulation. 1994;89:635-41.

2. Teoh KH, Ivanov J, Weisel RD, Darcel IC, Rakowski H. Survival and bioprosthetic valve failure. Ten-year follow up. Circulation. 1989; 80(Suppl 1):8-15.

3. Kirklin JK, Smith D, Novick W, Naftel DC, Kirklin JW, Pacifico AD, et al. Long-term function of cryopreserved aortic homografts. J Thorac Cardiovasc Surg. 1993;106:154-66.

4. Sodian R, Hoerstrup SP, Sperling JS, Daebritz SH, Martin DP, Schoen FJ, et al. Tissue engineering of heart valves: in vitro experiences. Ann Thorac Surg. 2000;70:140-4.

5. Bader A, Steinhoff G, Strobl K, Schilling T, Brandes G, Mertsching H, et al. Engineering of human vascular tissue based on a xenogeneic starter matrix. Transplantation. 2000;70:7-14.

6. Steinhoff G, Stock U, Najibulla K, Mertsching H, Timke A, Meliss R, et al. Tissue engineering of pulmonary heart valves on allogenic acellular matrix conduits: in vivo restoration of valve tissue. Circulation. 200;102(Suppl III):III50-5.

7. Allaire E, Guettier C, Bruneval P, Plissonier D, Michel JB. Cell-free arterial grafts: morphologic characteristics of aortic isografts, allografts and xenografts in rats. J Vasc Surg. 1994;19:446-56.

8. Booth C, Korossis SA, Wilcox HE, Watterson KG, Kearney JN, Fisher $\mathrm{J}$, et al. Tissue engineering of cardiac valve prosthesis I: development and histological characterization of an acellular porcine scaffold. J Heart Valve Dis. 2002;11:457-62.

9. Samouillan V, Dandurand-Lods J, Lamure A, Maurel E, Lacabanne C, Gerosa G, et al. Thermal analysis characterization of aortic tissues for cardiac valve bioprostheses. J Biomed Mater Res. 1999;46:531-5.

10. Conant AR, Fisher MJ, McLennan AG, Simpson AW. Diadenosine polyphosphates are largely ineffective as agonists at natively expressed P2Y(1) and P2Y(2) receptors on cultured human saphenous vein endothelial cells. J Vasc Res. 2000;37:548-55.

11. Jaffe EA, Nachmann RL, Becker CG, Minick CR. Culture of human endothelial cells derived from umbilical veins. Identification by morphologic and immunologic criteria. J Clin Invest. 1973;52:2745-56.

12. Vesely I, Noseworthy R, Pringle G. The hybrid xenograft/autograft bioprosthetic heart valve: in vivo evaluation of tissue extraction. Ann Thorac Surg. 1995;60:359-64.

13. Allaire E, Bruneval P, Mandet C, Becquemin JP, Michel JB. The immunogenicity of the extracellular matrix in arterial xenografts. Surgery. 1997;122:73-81.

14. O'Brien M, Goldstein S, Walsh S, Black K, Elkins R, Clarke D. The Synergraft valve: a new acellular (nonglutaraldehyde-fixed) tissue heart valve implantation. Semin Thorac Cardiovasc Surg. 1999;11: 194-200.

15. Patience C, Takeuchi Y, Weiss RA. Infection of human cells by an endogenous retrovirus of pigs. Nat Med. 1997;3:282-6.

16. Martin U, Kiessig V, Blusch JH, Haverich A, von der Helm K, Herden T. Expression of pig endogenous retrovirus by primary porcine endothelial cells and infection of human cells. Lancet. 1998;352:692-4.

17. Martin U, Tacke S, Simon AR, Schroeder C, Wiebe K, Lapin B. Absence of PERV specific humoral immune response in baboons after transplantation of porcine cells or organs. Transpl Int. 2002; 15:361-8.

18. Bordenave L, Remy-Zoghadri M, Fernandez, Bareille R, Midy D. Clinical performance of vascular grafts lined with endothelial cells. Endothelium. 1999;64:267-75.

19. Simon P, Kasimir MT, Seebacher G, Weigel G, Ullrich R, SalzerMuhar U, et al. Early failure of the tissue engineered porcine heart valve Synergraft TM in pediatric patients. Eur J Cardiothorac Surg. 2003;23:1002-6

20. Magometschnig H, Kadletz M, Vodratzka M, Dock W, Grimm W, 
Grabenwoeger M, et al. Prospective clinical study with in vitro endothelial cell lining of expanded polytetrafluoroethylene grafts in crural repeat reconstruction. J Vasc Surg. 1992;15:527-35.

21. Meinhart JG, Deutsch M, Fischlein T, Howanietz N, Froschl A, Zilla P. Clinical autologous in vitro endothelialization of 153 infrainguinal ePTFE grafts. Ann Thorac Surg. 2001;71:327-31.

22. Schneider PA, Hanson SR, Price TM, Harker LA. Confluent durable endothelialization of endarterectomized baboon aorta by early attachment of cultured endothelial cells. J Vasc Surg. 1990;11:36572.

23. Shinoka T, Breuer C, Tanel R, Zund G, Miura T, Ma PX, et al. Tissue engineering heart valves: valve leaflet replacement study in a lamb model. Ann Thorac Surg. 1995;60:513-6.

24. Shinoka T, Shum-Tim D, Ma PX, Tanel RE, Isogai N, Langer R, et al.
Creation of a viable pulmonary artery autograft through tissue engineering. J Thorac Cardiovasc Surg. 1998;115:536-46.

25. Bader A, Schilling T, Teebken OE, Brandes G, Heredn T, Steinhoff G, et al. Tissue Engineering of heart valves human endothelial cell seeding of detergent acellularized porcine valves. Eur J Cardiothoracic Surg. 1998; 14:279-84.

26. Galili $\mathrm{U}$. The - gal epitope (Gal 1-3Gal 1-4GlcNAc-R) in xenotransplantation. Biochimie. 2001;83:557-63.

27. Bodnar E, Olsen EG, Florio R, Dobrin J. Damage of porcine aortic valve tissue caused by the surfactant sodiumdodecylsulphate. Thorac Cardiovasc Surg. 1986;34:82-5.

28. Kim WG, Park JK, Lee WY. Tissue-engineered heart valve leaflets: an effective method of obtaining acellularized valve xenografts. Int J Artif Organs. 2002;25:791-7. 